\title{
The wave-driven current in coastal canopies
}

2 Maryam Abdolahpour, ${ }^{1,2}$ Magnus Hambleton, ${ }^{1}$ and Marco Ghisalberti ${ }^{1,3}$

Corresponding author: M. Abdolahpour, School of Civil, Environmental and Mining Engineering, University of Western Australia (M015), 135 Stirling Highway, Perth, WA 6009, Australia. (maryam.abdolahpour@uwa.edu.au)

${ }^{1}$ School of Civil, Environmental and

Mining Engineering, University of Western

Australia, Perth, WA 6009, Australia

${ }^{2}$ School of Natural Sciences, Edith Cowan

University, Joondalup, WA 6027, Australia

${ }^{3}$ Department of Infrastructure

Engineering, University of Melbourne,

Parkville, VIC 3010, Australia 


\section{Key Points.}

- Wave-driven flows over a canopy generate a strong mean current which can be up to $75 \%$ of the RMS orbital velocity far above the canopy.

- The strength of this current, which is centered near the top of the canopy, increases with vertical orbital excursion and canopy density.

- The characterization of the mean current presented here will allow an enhanced capacity for the description of canopy residence time in wavedominated systems.

3 Abstract. Wave-driven flows over canopies of aquatic vegetation (such

${ }_{4}$ as seagrass) are characterized by the generation of a strong, shoreward mean

${ }_{5}$ current near the top of the canopy. This shoreward drift, which is observed

6 to be up to $75 \%$ of the RMS above-canopy orbital velocity, can have a sig-

7 nificant impact on residence times within coastal canopies. There have been

s limited observations of this current and an accurate formulation of its mag-

9 nitude is still lacking. Accordingly, this study aims to develop a practical re-

10 lationship to describe the strength of this current as a function of both wave

11 and canopy characteristics. A simple model for the Lagrangian drift veloc-

12 ity indicates that the magnitude of the wave-driven current increases with

${ }_{13}$ the above-canopy oscillatory velocity, the vertical orbital excursion at the

${ }_{14}$ top of the canopy and the canopy density. An extensive laboratory study,

15 using both rigid and (dynamically-scaled) flexible model vegetation, was car-

${ }_{16}$ ried out to evaluate the proposed model. Experimental results reveal a strong

${ }_{17}$ agreement between predicted and measured current velocities over a wide

${ }_{18}$ and realistic range of canopy and wave conditions. The validity of this model

${ }_{19}$ is also confirmed through available field measurements. Characterization of 
${ }_{20}$ this wave-induced mean current will allow an enhanced capacity for predict-

${ }_{21}$ ing residence time, and thus key ecological processes, in coastal canopies. 


\section{Introduction}

Rough benthic boundaries are ubiquitous in the coastal environment and include a multitude of ecologically-important aquatic ecosystems, such as seagrass meadows [Duarte, ${ }_{24}$ 2002], coral reefs [Monismith, 2007] and kelp forests [Rosman et al., 2007]. The drag exerted by these coastal canopies reduces the near-bed velocity and attenuates wave en${ }_{26}$ ergy [Kobayashi et al., 1993; Manca et al., 2012; Maza et al., 2015]. This, in turn, promotes ${ }_{27}$ sedimentation [Gacia et al., 1999], carbon burial [Granata et al., 2001] and retention of par${ }_{28}$ ticulate material [Fonseca and Cahalan, 1992; Granata et al., 2001; French, 2006]. Thus, ${ }_{29}$ besides providing food and shelter for a range of species [Gambi et al., 1990; Koch et al., 30 2006], aquatic canopies can enhance light penetration and promote productivity [Gruber 31 and Kemp, 2010; Gruber et al., 2011]. In addition, aquatic canopies play an essential role 32 in regulating water quality through the direct uptake of nutrients and dissolved organic 33 matter [Moore, 2004; Larkum et al., 2006] as well as the production of oxygen [Carpenter ${ }_{34}$ and Lodge, 1986; Larkum et al., 2006].

${ }_{35}$ The capacity of an aquatic canopy to provide these ecosystem services is tightly limited

${ }_{36}$ by the exchange of water across canopy boundaries [Duarte, 1995]. Rapid exchange also ${ }_{37}$ has a tremendous impact on particle mobility [Palmer et al., 2004], including the transport 38 of pollen [Ackerman, 1997, 2002; Dupont et al., 2006] and dispersal of seeds [Orth et al., 39 1994]. It may also prevent coral bleaching [Nakamura and Van Woesik, 2001] and the loss 40 of symbiotic algae from the tissue of the coral polyps [Hoegh-Guldberg, 1999]. Therefore, ${ }_{41}$ the ecological health and propagation and environmental influence of coastal canopies 
${ }_{42}$ depends largely on the exchange, and thus residence time, of dissolved and particulate materials in these systems.

${ }_{44}$ In coastal canopy environments, the impact of advection on residence time is often ne-

45 glected [Abdolahpour et al., 2017]. Although coastal systems are typically wave-dominated,

${ }_{46}$ this impact may not, however, necessarily be small. Indeed, aquatic canopies in oscillatory

47 flows have been shown to generate a strong, shoreward mean current near the canopy-

${ }_{48}$ water interface [Luhar et al., 2010]. This shoreward drift, which has been observed in

${ }_{49}$ both laboratory [Lowe et al., 2005a; Luhar et al., 2010] and field studies [Luhar et al.,

50 2013], can significantly influence canopy residence time by introducing a second method

${ }_{51}$ of water renewal (other than vertical mixing across the top of the canopy).

${ }_{52}$ This mean current can also substantially modify the posture of flexible canopy, as shown

${ }_{53}$ in Figure 1. The shoreward current creates a more pronated canopy in the direction of

${ }_{54}$ wave propagation under the wave crest (Figure 1a) and a more upright posture under the

${ }_{58}$ caused by the reconfiguration of flexible canopies can greatly diminish wave attenuation

${ }_{59}$ [Maza et al., 2015]. Extreme canopy pronation (under, for example, storm conditions) can also increase the rate of stem fracture along the line of weakness, resulting in plant

${ }_{61}$ loss and further reduced wave attenuation [Möller et al., 2014].

In coastal systems, vertical gradients in oscillatory velocity are known to drive mean ${ }_{63}$ currents, including the Stokes drift near the surface [Dean and Dalrymple, 1991; Nielsen, $\left.{ }_{64} \quad 1992\right]$ and boundary layer streaming near the bed [Fredsøe and Deigaard, 1992]. Al- 


\section{X - 6 ABDOLAHPOUR ET AL.: WAVE-DRIVEN MEAN CURRENT IN COASTAL CANOPIES}

${ }_{65}$ though Stokes drift is the manifestation of open orbits of fluid particles, boundary layer

${ }_{66}$ streaming is believed to be a consequence of a shear-induced non-zero temporal corre-

${ }_{67}$ lation of horizontal and vertical oscillatory velocities, which creates a wave stress near

${ }_{68}$ the bed [Scandura, 2007; Kranenburg et al., 2012]. For laminar flow over a flat bed, this

${ }_{69}$ results in a shoreward mean current within the boundary layer [Longuet-Higgins, 1953].

In coastal canopy flows, the drag exerted by the canopy results in a vertical gradient

${ }_{71}$ of orbital velocity across the canopy-water interface. That is, the velocity within the

72 canopy, $U_{c}^{r m s}$ (where the superscript 'rms' refers to the root-mean-square of the oscillatory

${ }_{73}$ velocity and the subscript ' $c$ ' to the in-canopy average), is attenuated from its value far

${ }_{74}$ above the canopy, $U_{\infty}^{r m s}$ (Figure 2). This velocity attenuation, which is greater for denser

75 canopies [Lowe et al., 2005b; Reidenbach et al., 2007; Pujol et al., 2013], creates a shear

76 layer across the top of the canopy (as seen in steady flows).

77 Previous research has hypothesized that velocity shear near the canopy top is the source

${ }_{78}$ of the shoreward mean current in coastal canopies through a mechanism analogous to

79 boundary layer streaming [Luhar et al., 2010, 2013]. By quantifying the wave Reynolds

so stress set up by a submerged canopy, and balancing that against canopy drag, Luhar et al.

${ }_{81}[2010]$ established a theoretical model for the mean drift within the canopy:

$$
\bar{u}_{c}=\sqrt{\frac{4}{3 \pi} \frac{C_{D w}}{C_{D c}} \frac{k}{\omega} U_{c}^{3}}
$$

${ }_{82}$ where $\bar{u}_{c}$ is the vertically-averaged in-canopy mean current, $C_{D w}$ and $C_{D c}$ are the time-

8з varying and steady components of the drag coefficient (respectively), $k$ is the wavenumber,

${ }_{84} \omega$ is the wave radian frequency and $U_{c}$ is the amplitude of the in-canopy oscillatory velocity. 
${ }_{85}$ It was assumed that $U_{c}$ is equal to the near-bed velocity amplitude in the absence of the

${ }_{86}$ canopy $\left(U_{b}\right)$, which can be predicted from linear wave theory:

$$
U_{b}=\frac{H \omega}{2 \sinh k h}
$$

${ }_{\text {87 }}$ where $H$ is the wave height and $h$ is the water depth. For simplicity, $C_{D w} / C_{D c}$ was as-

${ }_{88}$ sumed to be one. Generally, reasonable agreement was observed between the formulation

${ }_{89}$ in (1) and laboratory measurements when the RMS horizontal orbital excursion above

${ }_{90}$ the canopy $\left(A_{\infty}^{r m s}=U_{\infty}^{r m s} / \omega\right)$ exceeded the stem-to-stem distance of canopy elements

${ }_{91}(S)$ Luhar et al., 2010]. The model underpredicts (by a factor of nearly 3) the mean current generated in the field during periods of strong waves [see field measurements by

93 Luhar et al., 2013]; an improvement is achieved in subsequent work when a time-varying

${ }_{94}$ frontal area of the flexible canopy is introduced [Luhar et al., 2013].

${ }_{95}$ Despite the reasonable agreement between model and experiment, the impact of canopy 96 density is absent from the formulation in (1), meaning that is likely valid over only a lim${ }_{97}$ ited range of coastal canopies. We hypothesize here that any roughness-driven current ${ }_{98}$ must be dependent upon the density of the canopy. Accordingly, as a step towards improv-

99 ing estimation of canopy residence time, this study aims to use wave flume experiments to develop an alternate model for the strength of mean currents generated in wave-dominated 


\section{X - 8 ABDOLAHPOUR ET AL.: WAVE-DRIVEN MEAN CURRENT IN COASTAL CANOPIES}

\section{Model development} Cohen, 1990].

In the absence of a canopy, fluid particles under a small-amplitude wave have sinusoidally-varying velocities with closed elliptical trajectories (Figure 3a). However, the near-surface vertical gradient in orbital velocity causes fluid particles to travel faster in the direction of wave propagation at the top of their orbit than in the opposite direction at the bottom of their orbit. This leads to open particle orbits and a time-averaged mean current (the Stokes drift) in the direction of wave propagation [Nielsen, 1992; Kundu and

In the presence of a submerged canopy, a similar vertical velocity gradient is generated near the canopy-water interface (Figure 2). As the Lagrangian view in Figure 3a illustrates, this will result in open particle orbits and a Lagrangian mean current in the direction of wave propagation that is analogous to Stokes drift, albeit with a different underlying cause [Jacobsen, 2016]. Importantly, this drift is manifest in fixed-point velocity records (as seen for Stokes drift [Umeyama, 2010, 2012]), as oscillating fluid particles move with the drift during their shoreward motion and against it during their seaward motion. Thus, the oscillatory velocity amplitude is enhanced in the onshore direction and reduced in the offshore direction, leading to a non-zero measured mean velocity (Figure 3b). The vertical profile of mean velocity $(\bar{u})$ for a typical wave $\left(T=5 \mathrm{~s}\right.$ and $\left.U_{\infty}^{r m s}=19 \mathrm{~cm} / \mathrm{s}\right)$ along with the horizontal velocity signals at the top of, and far above, the canopy, clearly show the oscillatory velocity asymmetry resulting from this mechanism (Figure 3b).

It is expected that the strength of the mean current at any given height will be directly proportional to the maximum velocity difference experienced by fluid particles whose orbits encompass that height. We assume that the maximum velocity, $\bar{u}_{\max }$, occurs at the 


$$
\bar{u}_{\max } \sim \delta U
$$

where

$$
\delta U=u_{\left(h_{c}+\xi_{T}\right)}^{r m s}-u_{\left(h_{c}-\xi_{T}\right)}^{r m s}
$$

130

131

${ }_{138}$ length scale, $L_{D}$ [Abdolahpour et al., 2017]:

$$
\bar{u}_{\text {max }} \sim \delta U=f\left(U_{\infty}^{r m s}, \xi_{T}, L_{D}\right)
$$

${ }_{141}$ A simple dimensional reasoning solution to (6) is: 


$$
\frac{\bar{u}_{\max }}{U_{\infty}^{r m s}}=f\left(\frac{\xi_{T}}{L_{D}}\right)
$$

\section{Methods}

\subsection{Experimental setup} mined using experimental data.

To develop a predictive formulation for $\bar{u}_{\max }$, the functional form of $(7)$ will be deter-

Experiments were conducted in a 50-m-long, 1.2-m-deep and 1.2-m-wide wave flume (Figure 4 ) with a still water depth $(h)$ of $0.76 \mathrm{~m}$. The wave flume was equipped with a programmable piston-type wave generator located in the middle of the flume. Wooden beaches of slope $1: 10$ were installed at both ends of the flume. The beaches were covered with rubber mats at the front and less porous Polyetherane filter foam at the back so that incident waves encountered regions of progressively decreasing porosity. The beach length exceeded the incident wavelength in all experiments. The reflection coefficient in the flume was estimated by measuring wave height along a transect parallel to the direction of wave propagation, with the difference between the maximum and minimum wave heights along 3 the transect used to quantify reflection [see Abdolahpour et al., 2017, for more detail]. 54 For wave conditions typical of this study, the reflection coefficient of the flume varied from $2-10 \%$. This level of reflection, while causing slight spatial variation in local wave ${ }^{56}$ heights and orbital velocities, has invariably been deemed negligible in previous studies investigating the generation of time-averaged currents under waves [e.g. Sleath, 1985; Villaret and Perrier, 1992; Luhar et al., 2010; Umeyama, 2012]. 


\subsection{Model vegetation}

$$
B=\frac{F_{B}}{F_{R}} \sim \frac{\left(\rho_{w}-\rho_{s}\right) g h_{b}^{3}}{E t^{2}}
$$

[Ghisalberti and Nepf, 2002; Luhar and Nepf, 2011]. Here, $\rho_{w}$ and $\rho_{s}$ are the densities of water and seagrass, respectively, $t$ is the blade thickness, $h_{b}$ is the blade height and $E$ is the modulus of elasticity, which describes the resistance of the blade to deformation. Blades with low values of $B$ exhibit cantilever-like motion, while those with higher values exhibit a more 'whip-like' motion [Ghisalberti and Nepf, 2002]. The second dimensionless ratio, the Cauchy number $(\mathrm{Ca})$, represents the ratio of the drag force on the blade, $F_{D}$, to the restoring force: 


$$
C a=\frac{F_{D}}{F_{R}} \sim \frac{\rho_{w} C_{D}\left(U_{c}^{r m s}\right)^{2} h_{b}^{3}}{E t^{3}},
$$


ABDOLAHPOUR ET AL.: WAVE-DRIVEN MEAN CURRENT IN COASTAL CANOPIES X - 13

multispecific systems, a single value of flexibility (and, indeed, canopy height) may not accurately characterize the entire canopy.

Three rigid canopies with dimensionless frontal area $a d=0.016,0.063$ and 0.131 (denoted as RL, RM and RH hereafter) were employed (Table 1). In the flexible canopies, as each canopy element consisted of two blades of differing heights, the canopy frontal area varied over depth. We therefore describe flexible canopies through their verticallyaveraged dimensionless frontal area $a b_{\text {eff }}$ (Figure 6). Note that $a b_{\text {eff }}$ is the dimensionless frontal area of the canopy based on the full blade height and width (i.e. for the canopy being completely upright and perpendicular to the flow). Two flexible canopies with $a b_{e f f}=0.064$ and 0.145 (denoted as FM and FH hereafter), were used. The ranges of $a d$ $(0.016-0.131)$ and $a b_{e f f}(0.064-0.145)$ employed here (Table 1) span typical densities of coastal canopies [Gambi et al., 1990; Luhar et al., 2010].

The canopy height $\left(h_{c}=30 \mathrm{~cm}\right)$ and stem diameter for rigid canopies $(d=0.64 \mathrm{~cm})$, the blade height $\left(h_{b}=30 \mathrm{~cm}\right)$ and width for flexible canopies $(b=1 \mathrm{~cm})$ as well as water depth $(h=0.76 \mathrm{~m})$ were kept constant throughout the experiments. The canopy length $(l)$ was varied inversely with the canopy density (ranging from 3-9 m, Table 1 ). To minimize edge effects, the length of the canopy on either side of the measurement location was at least four times the total horizontal orbital excursion far above the canopy.

Each canopy was exposed to up to nineteen flow conditions by varying the wave period $(T=5-9 \mathrm{~s})$ and above canopy RMS velocity $\left(U_{\infty}^{r m s}=3.0-21.5 \mathrm{~cm} / \mathrm{s}\right)($ Table 2$)$. All generated waves were shallow-water waves with $k h \leqslant 0.35$ [Dean and Dalrymple, 1991], typical of coastal seagrass meadows [Koch et al., 2006]. 


\section{X - 14 ABDOLAHPOUR ET AL.: WAVE-DRIVEN MEAN CURRENT IN COASTAL CANOPIES}

\subsection{Velocity measurements}

Vertical profiles of velocity were taken in the middle of the canopy using an Acoustic Doppler Velocimeter (ADV). In rigid canopies, data points were spaced every $2 \mathrm{~cm}$; in flexible canopies, velocity data were taken every $1 \mathrm{~cm}$ for $z<16 \mathrm{~cm}$, and every $2 \mathrm{~cm}$ for $z \geq 16 \mathrm{~cm}$ to focus on the near-bed region where the velocity gradient was expected to be greatest.

In dense rigid canopies (i.e. $\mathrm{RM}$ and $\mathrm{RH}$ ), a small area (of $\sim 5$-cm diameter) was cleared of dowels to allow ADV access into the canopy (Figure 4). It was observed here that the larger clearing required to allow ADV access inside flexible canopies [e.g. Neumeier and Ciavola, 2004; Pujol et al., 2010] significantly altered the magnitude of RMS velocities and mean current near the top of the canopy (by up to $30 \%$ and $20 \%$, respectively). Therefore, the flexible canopies were not modified; instead, ADV data inside the canopy that were contaminated by model blades entering the sampling volume (as indicated by beam correlations $<70 \%$ ) were excluded from analysis. The excluded data points were distributed quasi-randomly throughout the wave cycle, such that data exclusion did not significantly bias the estimated flow statistics. The extent of data exclusion was small with less than $1 \%$ of the data excluded in nearly all records. Figure 7a shows a typical profile of RMS velocities (Run 18-FM in Table 1) obtained from raw and filtered data. Filtering the data does not significantly alter the estimates of $U_{\infty}^{r m s}$ (Figure 7a) and current speed (Figure 7b). It does, however, impact RMS velocity estimates in the vicinity of the top of the canopy, but this is not critical to the analysis presented here. Filtered data were therefore used for all flexible canopies in this study. 
ABDOLAHPOUR ET AL.: WAVE-DRIVEN MEAN CURRENT IN COASTAL CANOPIES X - 15

${ }_{256}$ in the direction of wave propagation, $U^{r m s}$, was calculated according to:

$$
U^{r m s}=\sqrt{\frac{1}{2 \pi} \int_{-\pi}^{\pi}(\langle u(\varphi)\rangle-\bar{u})^{2} d \varphi}
$$

${ }_{257}$ where the angular brackets represent the phase average over several wave periods.

\subsection{Vertical orbital excursion}

The vertical orbital excursion at the top of the canopy $\left(\xi_{T}\right)$ was calculated according to 259 linear wave theory:

$$
\xi_{T}=\frac{H}{2} \frac{\sinh \left(k h_{c}\right)}{\sinh (k h)}
$$




\section{X - 16 ABDOLAHPOUR ET AL.: WAVE-DRIVEN MEAN CURRENT IN COASTAL CANOPIES}

${ }_{260}$ [Dean and Dalrymple, 1991]. For flexible canopies, the vertical orbital excursion was

\section{Results}


ABDOLAHPOUR ET AL.: WAVE-DRIVEN MEAN CURRENT IN COASTAL CANOPIES $\quad$ X - 17

${ }_{282}$ low, ranging from $6-20 \%$ of $\bar{u}_{\max }$. Thus, the closed nature of the flume may induce

${ }_{283}$ discrepancies (relative to open systems) of this order. The time-averaged velocity near

${ }_{284}$ the canopy top exceeds the velocity in the absence of the canopy by at least an order

285 of magnitude, implying that the closed nature of the wave flume negligibly impacts the

${ }_{286}$ currents generated at the top of the experimental canopies. Through conservation of mass,

${ }_{287}$ the strong current at the top of the canopy creates weak compensating return flows well

${ }_{288}$ above and below the canopy shear layer in the closed experimental system (Figure 8).

\subsection{Variation of $\bar{u}$}




\subsection{Prediction of wave-driven mean current} here.

Equation (1) does not accurately predict the magnitude of the currents observed here (Figure 10). The observed depth-averaged current inside the canopy $\left(\bar{u}_{c}\right)$ is plotted against the Equation (1) prediction for the flexible canopies of this study (given that the formulation was initially tested on data from flexible canopies). In Figure 10a, the amplitude of the in-canopy oscillatory velocity, $U_{c}$, is estimated from linear wave theory assuming no velocity attenuation by the canopy (i.e. $U_{c} \equiv U_{b}$ in Equation (2), as per Luhar et al. [2010]); in Figure 10b, the measured value of $U_{c}$ in these experiments is used. While both definitions of $U_{c}$ provide reasonably accurate predictions of the depth-averaged current speed in the experiments of Luhar et al. [2010], neither one allows accurate predictions within the comparatively dense canopies studied here. The clear relationship between canopy density and current strength (Figure 9b) means that Equation (1) cannot provide accurate estimates across the range of densities of real coastal canopies; as shown in Figure 10b, the model clearly underpredicts the current strength for dense canopies. Thus, it is imperative that a density-dependent formulation for the current strength be developed

We first evaluate the hypothesis that this current is driven by the velocity differential experienced by particles during their orbit. To do this, the dependence of $\bar{u}_{\max }$ on the velocity difference experienced by particles at the top of the canopy ( $\delta U$, Equation (4)) is examined across all runs with rigid canopies (Figure 11). The magnitude of the current is directly proportional to $\delta U\left(\mathrm{R}^{2}=0.80\right)$ with an $O(1)$ coefficient of proportionality. This strongly supports the hypothesis underlying a model of a velocity-gradient-driven current at the canopy top. 


$$
\bar{u}_{\text {max }}=0.5 U_{\infty}^{r m s}\left(\frac{\xi_{T}}{L_{D}}\right)^{0.3}
$$

${ }_{326}$ As shown in Figure 12, there is a strong collapse $\left(\mathrm{R}^{2}=0.83\right)$ when observed current speeds ${ }_{327}$ are compared to Equation (12) across the range of canopies (rigid and flexible, dense and sparse) employed here. This model also demonstrates strong agreement with the

\subsection{Advective flux}




\section{X - 20 ABDOLAHPOUR ET AL.: WAVE-DRIVEN MEAN CURRENT IN COASTAL CANOPIES}

${ }_{345}$ scale is normalized by the vertical orbital excursion, $\xi_{T}$ (Figure 13). The scatter of data ${ }_{346}$ in the upper regions of the water column (i.e. above the shear layer) is likely due to the ${ }_{347}$ compensating return flow generated in the closed system. Due to canopy resistance, this 348 compensating flow is preferentially diverted above the canopy (as seen in Figures 8 and 9).

349 It is noteworthy that the significant mean current is confined to one vertical orbital excur350 sion above and below the canopy-water interface; i.e. $-1<\left(z-h_{c}\right) / \xi_{T}<1$ (Figure 13). ${ }_{351}$ This further supports the model developed in Section 2 (Figure 3), where only particles 352 whose orbits span the shear layer at the canopy top experience the Lagrangian drift. The ${ }_{353}$ region of non-zero shoreward velocity (highlighted in Figure 13) extends slightly higher ${ }_{354}$ than this, however. This is because the shear layer that forms at the top of the canopy 355 is (a) of non-zero thickness, and (b) is centered above the canopy top. Therefore, fluid ${ }_{356}$ particles that sample a gradient in oscillatory velocity in their orbits (and thus experience ${ }_{357}$ a shoreward drift) can exist above $z=h_{c}+\xi_{T}$. The region of non-zero shoreward velocity 358 indeed extends above this point (Figure 13).

${ }_{359}$ Guided by the average point of zero-crossing of the mean velocity profiles, the total 360 advective flux $(q)$ generated by the canopy was estimated by integration of the velocity 361 profile from $-1<\left(z-h_{c}\right) / \xi_{T}<2$, i.e.

$$
q=\int_{h_{c}-\xi_{T}}^{h_{c}+2 \xi_{T}} \bar{u} d z
$$

${ }_{362}$ Given the collapse observed in Figure 13, the integral in Equation (13) scales simply on ${ }_{363} \bar{u}_{\max } \xi_{T}$, such that:

$$
q=\gamma \bar{u}_{\max } \xi_{T}
$$


ABDOLAHPOUR ET AL.: WAVE-DRIVEN MEAN CURRENT IN COASTAL CANOPIES $\quad$ X - 21 ${ }^{364}$ where $\gamma$ is the scaling coefficient determined by experiment. There is a clear linear re-

365 lationship $\left(\mathrm{R}^{2}=0.86\right)$ between the total observed advective flux in rigid canopies $\left(q_{r}\right.$, 366 calculated from (13)) and observed values of $\left(\bar{u}_{\max } \xi_{T}\right)$ (Figure 14). The coefficient of 367 proportionality is $\gamma=1.2$.

\subsubsection{Flexible canopies}

Description of the total flux for flexible canopies is challenging due to the variation of the canopy height over the wave cycle. This creates a wider vertical region within which the current is generated (Figure 15). In this figure, a constant canopy height of $h_{c}=30$ $\mathrm{cm}$ is employed in defining the normalized vertical scale $\left(z-h_{c}\right) / \xi_{T}$, for consistency with rigid canopies. Unlike in rigid canopies, vertical profiles of the mean current do not exhibit a collapse, with the location of maximum velocity varying with wave conditions. Moreover, the maximum velocity consistently occurs at lower levels than in rigid canopies, due presumably to pronation of the canopy during the wave cycle. Notwithstanding the uncertainties associated with the time-varying canopy height, Figure 15 suggests that $\bar{u}$ contributes to the shoreward mass flux, predominantly, within a region of thickness $3 \xi_{T}$ centered around the maximum velocity, consistent with rigid canopies. Evaluating mass flux within this region for each run results in a clear scaling of $q_{f}$ (where $q_{f}$ is the total advective flux in flexible canopies) on $\left(\bar{u}_{\max } \xi_{T}\right)$ (Figure 16). The coefficient of proportionality for flexible canopies is $\gamma=1.9$. This is greater than that for rigid canopies, due to the more diffuse profile of mean velocity in flexible canopies.

The greater value of $\gamma$ for flexible canopies is not unexpected, due to the asymmetry in canopy drag. In flexible canopies, fluid particles experience a lower canopy drag when moving in the shoreward direction and a greater drag when moving in the seaward direc- 


\section{X - 22 ABDOLAHPOUR ET AL.: WAVE-DRIVEN MEAN CURRENT IN COASTAL CANOPIES}

${ }_{387}$ tion because of the asymmetry in the plant posture through the wave cycle (Figure 1). This asymmetry will lead to an increased velocity differential experienced by fluid particles

389 in the region of significant flow and, ultimately, a stronger mean current generation.

\subsection{Implications for predicting residence time in real canopies}

${ }_{403}$ absence of return flows).

\section{Conclusion}

404 
${ }_{407}$ of the canopy in the direction of wave propagation. The maximum value of this current, ${ }_{408} \bar{u}_{\text {max }}$, can be as much as $75 \%$ of the RMS orbital velocity far above the canopy.

${ }_{409}$ In this study, a simple, practical formulation for the magnitude of this mean current is ${ }_{410}$ presented as a function of both wave and canopy conditions. The proposed formulation ${ }_{411}$ (Equation (12)), indicates that the maximum current speed $\left(\bar{u}_{\max }\right)$ increases with the

${ }_{413}$ canopy density. There is good agreement between observed currents and predicted values

${ }_{414}$ across a wide and realistic range of wave and canopy properties (including flexibility). This

${ }_{415}$ model can therefore be used for an accurate estimation of advective flux, and ultimately

${ }_{416}$ the residence time, in coastal canopies. The total mass flux generated by this mechanism

${ }_{417}$ is $q \simeq 1.2 \bar{u}_{\max } \xi_{T}$ for rigid canopies, with a slightly enhanced value $\left(q \simeq 1.9 \bar{u}_{\text {max }} \xi_{T}\right)$

${ }_{418}$ for flexible canopies. Characterization of this wave-induced mean current will allow an

${ }_{419}$ enhanced capacity for predicting residence time, and thus key ecological processes, in

420 coastal canopies.

${ }^{421}$ Acknowledgments. M. Abdolahpour gratefully acknowledges the support of a Collab${ }_{422}$ orative Research Network scholarship (CRN) and a Postgraduate Research Scholarship ${ }^{423}$ granted by Edith Cowan University (ECUPRS) and the Australian Government. This ${ }_{424}$ project was funded by a grant from the Australian Department of Innovation, Industry, ${ }_{425}$ Science and Research's Collaborative Research Network Scheme (Grant CRN2011:05). ${ }_{426}$ M. Hambleton would like to thank the UWA SWANS Scholarship for providing partial ${ }_{427}$ funding during this study. The authors would like to thank Mitul Luhar for providing ${ }_{428}$ experimental data used in Figure 10, Heidi Nepf for the insightful comments on this 
X - 24 ABDOLAHPOUR ET AL.: WAVE-DRIVEN MEAN CURRENT IN COASTAL CANOPIES

${ }_{429}$ manuscript, and two anonymous reviewers whose comments have helped to improve this manuscript. The data presented herein are available from the first author upon request.

\section{References}


ABDOLAHPOUR ET AL.: WAVE-DRIVEN MEAN CURRENT IN COASTAL CANOPIES X - 25

Dupont, S., Y. Brunet, and N. Jarosz (2006), Eulerian modelling of pollen dispersal over heterogeneous vegetation canopies, Agricultural and Forest Meteorology, 141(2), 82-104, doi:10.1016/j.agrformet.2006.09.004.

Fonseca, M. S., and J. A. Cahalan (1992), A preliminary evaluation of wave attenuation by four species of seagrass, Estuarine, Coastal and Shelf Science, 35(6), 565-576, doi: 10.1016/S0272-7714(05)80039-3.

Fredsøe, J., and R. Deigaard (1992), Mechanics of coastal sediment transport, vol. 3, World Scientific.

French, J. (2006), Tidal marsh sedimentation and resilience to environmental change: exploratory modelling of tidal, sea-level and sediment supply forcing in predominantly allochthonous systems, Marine Geology, 235(1), 119-136.

Gacia, E., T. Granata, and C. Duarte (1999), An approach to measurement of particle flux and sediment retention within seagrass (Posidonia oceanica) meadows, Aquatic Botany, 65(1), 255-268, doi:10.1016/S0304-3770(99)00044-3.

Gambi, M. C., A. R. Nowell, and P. Jumars (1990), Flume observations on flow dynamics in Zostera marina (eelgrass) beds, Marine Ecology Progress Series. Oldendorf, 61(1), 159-169, doi:10.3354/meps061159.

Ghisalberti, M., and H. M. Nepf (2002), Mixing layers and coherent structures in vegetated aquatic flows, Journal of Geophysical Research, 107(C2), 3011, doi: 10.1029/2001JC000871.

Granata, T., T. Serra, J. Colomer, X. Casamitjana, C. Duarte, E. Gacia, and J. Petersen (2001), Flow and particle distributions in a nearshore seagrass meadow before and after a storm, Marine Ecology Progress Series, 218, 95-106, doi:10.3354/meps218095. 


\section{X - 26 ABDOLAHPOUR ET AL.: WAVE-DRIVEN MEAN CURRENT IN COASTAL CANOPIES}

${ }_{473}$ Gruber, R. K., and W. M. Kemp (2010), Feedback effects in a coastal canopyforming submersed plant bed, Limnology and Oceanography, 55(6), 2285-2298, doi: 10.4319/lo.2010.55.6.2285. 
ABDOLAHPOUR ET AL.: WAVE-DRIVEN MEAN CURRENT IN COASTAL CANOPIES X - 27

${ }_{496}$ Kundu, P., and L. Cohen (1990), Fluid mechanics, 638 pp, Academic, Calif.

${ }_{497}$ Kuo, J. (1978), Morphology, anatomy and histochemistry of the australian seagrasses of

${ }_{498}$ the genus Posidonia könig (posidoniaceae). i. leaf blade and leaf sheath of posidonia australis hook f., Aquatic Botany, 5, 171-190.

Larkum, A. W., R. R. J. Orth, and C. M. Duarte (2006), Seagrasses: biology, ecology, and conservation, Springer.

Longuet-Higgins, M. S. (1953), Mass transport in water waves, Philosophical Transactions of the Royal Society of London. Series A, Mathematical and Physical Sciences, 245(903), $535-581$.

Lowe, R. J., J. R. Koseff, and S. G. Monismith (2005a), Oscillatory flow through submerged canopies: 1. velocity structure, Journal of Geophysical Research: Oceans (19782012), 110(C10), doi:10.1029/2004JC002788.

Lowe, R. J., J. R. Koseff, S. G. Monismith, and J. L. Falter (2005b), Oscillatory flow through submerged canopies: 2. canopy mass transfer, Journal of Geophysical Research: Oceans (19782012), 110(C10), doi:10.1029/2004JC002789.

Luhar, M., and H. Nepf (2015), Wave-induced dynamics of flexible blades, Journal of Fluids and Structures, 61, 20-41, doi:10.1016/j.jfluidstructs.2015.11.007.

Luhar, M., and H. M. Nepf (2011), Flow-induced reconfiguration of buoyant and flexible aquatic vegetation, Limnology and Oceanography, 56(6), 2003, doi: 10.4319/lo.2011.56.6.2003.

Luhar, M., S. Coutu, E. Infantes, S. Fox, and H. Nepf (2010), Wave-induced velocities inside a model seagrass bed, Journal of Geophysical Research: Oceans (1978-2012), 115(C12), doi:10.1029/2010JC006345. 
X - 28 ABDOLAHPOUR ET AL.: WAVE-DRIVEN MEAN CURRENT IN COASTAL CANOPIES

Luhar, M., E. Infantes, A. Orfila, J. Terrados, and H. M. Nepf (2013), Field observations of wave-induced streaming through a submerged seagrass (Posidonia oceanica) meadow, Journal of Geophysical Research: Oceans, 118(4), 1955-1968, doi:10.1002/jgrc.20162.

Manca, E., I. Caceres, J. Alsina, V. Stratigaki, I. Townend, and C. Amos (2012), Wave energy and wave-induced flow reduction by full-scale model posidonia oceanica seagrass, Continental Shelf Research.

Mass, T., A. Genin, U. Shavit, M. Grinstein, and D. Tchernov (2010), Flow enhances photosynthesis in marine benthic autotrophs by increasing the efflux of oxygen from the organism to the water, Proceedings of the National Academy of Sciences, 107(6), 2527-2531, doi:10.1073/pnas.0912348107.

Maza, M., J. Lara, I. Losada, B. Ondiviela, J. Trinogga, and T. Bouma (2015), Largescale 3-d experiments of wave and current interaction with real vegetation. part 2: experimental analysis, Coastal Engineering, 106, 73-86.

Mendez, F. J., and I. J. Losada (2004), An empirical model to estimate the propagation of random breaking and nonbreaking waves over vegetation fields, Coastal Engineering, $51(2)$, 103-118, doi:10.1016/j.coastaleng.2003.11.003.

Möller, I., M. Kudella, F. Rupprecht, T. Spencer, M. Paul, B. K. van Wesenbeeck, G. Wolters, K. Jensen, T. J. Bouma, M. Miranda-Lange, et al. (2014), Wave attenuation over coastal salt marshes under storm surge conditions, Nature Geoscience, 7(10), $727-731$.

Monismith, S. G. (2007), Hydrodynamics of coral reefs, Annual Review of Fluid Mechanics, 39, 37-55, doi:10.1146/annurev.fluid.38.050304.092125. 
ABDOLAHPOUR ET AL.: WAVE-DRIVEN MEAN CURRENT IN COASTAL CANOPIES X - 29

${ }_{541}$ Moore, K. A. (2004), Influence of seagrasses on water quality in shallow regions of the lower chesapeake bay, Journal of Coastal Research, pp. 162-178, doi:10.2112/SI45-162.1.

Nakamura, T., and R. Van Woesik (2001), Water-flow rates and passive diffusion partially explain differential survival of corals during the 1998 bleaching event, Marine Ecology Progress Series, 212, 301-304, doi:10.3354/meps212301.

Neumeier, U., and P. Ciavola (2004), Flow resistance and associated sedimentary processes in a spartina maritima salt-marsh, Journal of Coastal Research, pp. 435-447, doi:10.2112/1551-5036(2004)020[0435:FRAASP]2.0.CO;2.

Nielsen, P. (1992), Coastal bottom boundary layers and sediment transport, vol. 4, World Scientific.

Orth, R. J., M. Luckenbach, and K. A. Moore (1994), Seed dispersal in a marine macrophyte: implications for colonization and restoration, Ecology, 75(7), 1927-1939.

Palmer, M. R., H. M. Nepf, T. J. Pettersson, and J. D. Ackerman (2004), Observations of particle capture on a cylindrical collector: Implications for particle accumulation and removal in aquatic systems, Limnology and Oceanography, pp. 76-85, doi: 10.4319/lo.2004.49.1.0076

Pujol, D., J. Colomer, T. Serra, and X. Casamitjana (2010), Effect of submerged aquatic vegetation on turbulence induced by an oscillating grid, Continental Shelf Research, $30(9), 1019-1029$, doi:10.1016/j.csr.2010.02.014.

Pujol, D., T. Serra, J. Colomer, and X. Casamitjana (2013), Flow structure in canopy models dominated by progressive waves, Journal of Hydrology, 486, 281-292, doi: 10.1016/j.jhydrol.2013.01.024. 
X - 30 ABDOLAHPOUR ET AL.: WAVE-DRIVEN MEAN CURRENT IN COASTAL CANOPIES

${ }_{563}$ Raupach, M., P. Coppin, and B. Legg (1986), Experiments on scalar dispersion within

a model plant canopy part i: The turbulence structure, Boundary-Layer Meteorology, 35(1-2), 21-52, doi:10.1007/BF00117300.

Reidenbach, M. A., J. R. Koseff, and S. G. Monismith (2007), Laboratory experiments of fine-scale mixing and mass transport within a coral canopy, Physics of Fluids, 19, 075,107, doi:10.1063/1.2752189.

Rosman, J. H., J. R. Koseff, S. G. Monismith, and J. Grover (2007), A field investigation into the effects of a kelp forest (Macrocystis pyrifera) on coastal hydrodynamics and transport, Journal of Geophysical Research: Oceans, 112(C2), doi: 10.1029/2005JC003430.

Scandura, P. (2007), Steady streaming in a turbulent oscillating boundary layer, Journal of Fluid Mechanics, 571, 265-280, doi:10.1017/S0022112006002965.

Seginer, I., P. Mulhearn, E. F. Bradley, and J. Finnigan (1976), Turbulent flow in a model plant canopy, Boundary-Layer Meteorology, 10(4), 423-453, doi:10.1007/BF00225863.

Sleath, J. (1985), Measurements of mass transport over a rough bed, in Coastal Engineering 1984, pp. 1149-1160.

Umeyama, M. (2010), Coupled piv and ptv measurements of particle velocities and trajectories for surface waves following a steady current, Journal of Waterway, Port, Coastal, and Ocean Engineering, 137(2), 85-94.

Umeyama, M. (2012), Eulerian-lagrangian analysis for particle velocities and trajectories in a pure wave motion using particle image velocimetry, Philosophical Transactions of the Royal Society of London A: Mathematical, Physical and Engineering Sciences, $370(1964), 1687-1702$. 
${ }_{586}$ Villaret, C., and G. Perrier (1992), Transport of fine sand by combined waves and current:

${ }_{587}$ An experimental study, rep, Tech. rep., HE-42/92.68, Electr. de France, Chatou.

${ }_{588}$ Weitzman, J. S., R. B. Zeller, F. I. Thomas, and J. R. Koseff (2015), The attenuation

589 of current-and wave-driven flow within submerged multispecific vegetative canopies, Limnology and Oceanography, 60(6), 1855-1874.

Zimmerman, R. C. (2003), A biooptical model of irradiance distribution and photosynthesis in seagrass canopies, Limnology and Oceanography, 48(1; Part 2), 568-585, doi: 10.4319/lo.2003.48.1_part_2.0568. 
Figure 1. The impact of the wave-induced, shoreward mean current on a dynamically-scaled flexible canopy in the laboratory. Images show the canopy at its maximum pronation (a) in the direction of wave propagation, and (b) in the direction opposite to that of wave propagation. The presence of the mean current creates an asymmetry in canopy posture, with a greatly enhanced pronation in the direction of wave propagation. 
Figure 2. The increase in attenuation of orbital velocity with density in submerged canopies. Vertical profiles of RMS velocities for identical waves $\left(U_{\infty}^{r m s}=17 \mathrm{~cm} / \mathrm{s}\right.$, Run 18 in Table 2$)$ over a dense rigid canopy ( $10 \%$ by volume), a sparse rigid canopy ( $1 \%$ by volume) and a bare bed are presented. Values of the in-canopy RMS velocity, $U_{c}^{r m s}$, and the above-canopy RMS velocity, $U_{\infty}^{r m s}$, are indicated for the dense canopy. The gray dashed line represents the top of the canopy. 
Figure 3. Lagrangian and Eulerian views of the wave-induced drift over coastal canopies. (a) The deviation of particle orbits from linear wave theory (left) due to the canopy resistance. Fluid particles with a mean position at the top of the canopy will have a greater velocity in the direction of wave propagation $\left(U_{1}\right)$ than in the offshore direction $\left(U_{2}\right)$, generating a Lagrangian drift in the direction of wave propagation. (b) In spite of a symmetric oscillation far above the canopy $(\bar{u} \approx 0)$, fluid particles within approximately one vertical orbital excursion (i.e. $\pm \xi_{T}$ ) D R A F T March 22, 2017, 5:15pm D R A F T of the top of the canopy move with the drift under a wave crest and against it under a trough.

This generates an asymmetric Eulerian velocity record, such that $\bar{u} \neq 0$ near the canopy-water interface (shown for a typical wave with $T=5 \mathrm{~s}$ and $U_{\infty}^{r m s}=19 \mathrm{~cm} / \mathrm{s}$; Run 16-RM). 
Figure 4. Schematic view of the experimental configuration in the wave tank (not to scale). Beaches of slope 1:10 were constructed at both ends of the tank to minimize wave reflection. Velocity measurements were taken by an Acoustic Doppler Velocimeter (ADV) in the geometric center of the canopy. 
Figure 5. Photographs showing the ADV probe measuring within the densest (a) rigid and (b) flexible model canopies.

Figure 6. Vertical variation of dimensionless frontal area $(a b)$ in the model Posidonia australis canopy. The lower region of the canopy has a greater frontal area than the upper region. The average of the upper and lower values, $a b_{e f f}$, was used to characterize the flexible canopies. 
Figure 7. Vertical profiles of (a) $U_{r m s}$ and (b) $\bar{u}$ in Run 18-FM estimated using raw and filtered data. The shaded areas represent the top of the canopy (with spatial variability) at the point of the maximum pronation in the direction of wave propagation. Gray dashed lines indicate the maximum blade height. 
Figure 8. Vertical profiles of mean velocity in the absence and presence of the canopy. The observed vertical profile of mean velocity in the absence of a canopy (gray solid line) is in good agreement with the prediction of Longuet-Higgins [1953]. For the same wave $\left(U_{\infty}^{r m s}=19 \mathrm{~cm} / \mathrm{s}\right.$; Run 16, Table 2) in the presence of a canopy $(a d=0.063)$, the maximum current exceeds that in the absence of the canopy by an order of magnitude, typical of all the experimental runs conducted here. 
Figure 9. The impact of wave and canopy conditions on the mean current generated. (a) Identical rigid canopies $(a d=0.063$, Table 1$)$ subjected to different waves with $U_{\infty}^{r m s}$ between 3 and $19 \mathrm{~cm} / \mathrm{s}$. The stronger the wave forcing, the greater the mean current. (b) Identical waves $\left(U_{\infty}^{r m s}=19 \mathrm{~cm} / \mathrm{s}\right)$ over different rigid canopies with ad ranging from $0.016(\mathrm{~L})$ to $0.131(\mathrm{H}$, Table 1). Importantly, stronger currents are generated by denser canopies. (c) The maximum value of $\bar{u}$ occurs near the canopy top for both rigid and flexible canopies, which is indicated by D R A F T March 22, 2017, 5:15pm D R A F T a dashed line for the rigid canopy and a gray band (representing the range of blade heights at maximum pronation) for the flexible canopy. 
Figure 10. Observed (vertical axis) and predicted (horizontal axis) values of the depthaveraged current speed in the canopy $\left(\bar{u}_{c}\right)$ for two flexible canopy densities, $a b_{\text {eff }}=0.064$ and 0.145 (FM and FH, Table 1). Grey dashed lines indicate 1: 1 agreement. (a) Predicted value of $\bar{u}_{c}$ from (1), taking $U_{c} \equiv U_{b}$ as the in-canopy oscillatory velocity amplitude (Equation (2)), and (b) using values of $U_{c}$ measured in these experiments. While Equation (1) provides reasonably accurate predictions of the mean currents in the experiments of Luhar et al. [2010] (abbreviated D R A F T March 22, 2017, 5:15pm as LCIFN), it fails to do so in these experiments.

D R A F T 
Figure 11. The direct proportionality $\left(\mathrm{R}^{2}=0.80\right)$ in rigid canopies between the maximum current speed $\left(\bar{u}_{\max }\right)$ and the velocity differential experienced by particles that encounter the top of the canopy $(\delta U)$. The dashed line represents the line of the best fit. This validates the hypothesis in (3), which underpins the model presented here for wave-generated currents. 
Figure 12. The accuracy of the model developed here in predicting the maximum current, $\bar{u}_{\max }$. Observed $\bar{u}_{\max }$ values in both rigid and flexible canopies are in good agreement $\left(\mathrm{R}^{2}=0.83\right)$ with predicted values (from Equation (12)); the dashed line represents 1 : 1 agreement. Laboratory observations from Luhar et al. [2010] (only considering runs for which $A_{\infty}^{\text {rms }} / S<1$ ) and field observations from Luhar et al. [2013] (abbreviated as LIOTN) are also well predicted by (12). 
Figure 13. The collapse of vertical profiles of mean current speed on a normalized vertical scale $\left(\left(z-h_{c}\right) / \xi_{T}\right)$ for rigid canopies with (a) $a d=0.016$ (b) $a d=0.063$ and (c) $a d=0.131$. The darkness of the markers is proportional to the magnitude of $U_{\infty}^{r m s}$ (as indicated by the colorbar). The dashed lines indicate the region within one vertical orbital excursion of the canopy top and the gray bands the range over which the total advective flux was evaluated. 
Figure 14. The linear proportionality between the total flux in rigid canopies $\left(q_{r}\right)$ and $\left(\bar{u}_{\max } \xi_{T}\right)$. The strong proportionality $\left(R^{2}=0.86\right)$ validates the scaling relationship in (14) for rigid canopies. The slope of the line of best fit (dashed line) defines the scaling coefficient for rigid canopies, $\gamma(=1.2)$.

Figure 15. Profiles of $\bar{u} / \bar{u}_{\max }$ for the flexible canopy FH $\left(a b_{\text {eff }}=0.145\right)$ when plotted on a normalized vertical scale $\left(\left(z-h_{c}\right) / \xi_{T}\right)$. The darkness of markers is proportional to the magnitude of $U_{\infty}^{r m s}$ (as indicated by the colorbar). 
Figure 16. The linear proportionality between the total flux in flexible canopies $\left(q_{f}\right)$ and $\left(\bar{u}_{\text {max }} \xi_{T}\right)$. The strong proportionality $\left(R^{2}=0.80\right)$ validates the scaling relationship in (14). The slope of the line of best fit (dashed line) defines the scaling coefficient for flexible canopies, $\gamma$ $(=1.9)$. 
Table 1. Canopy densities employed in this study.

\begin{tabular}{ccccc} 
Canopy type & Density & $a d, a b_{\text {eff }}$ & $L_{D}(\mathrm{~m})$ & $l(\mathrm{~m})$ \\
\hline & L (Low) & 0.016 & 0.39 & 9 \\
Rigid (R) & M (Medium) & 0.063 & 0.10 & 5 \\
& H (High) & 0.131 & 0.05 & 3 \\
Flexible (F) & M (Medium) & 0.064 & 0.16 & 6 \\
& H (High) & 0.145 & 0.07 & 6 \\
\hline
\end{tabular}


Table 2. Wave conditions employed in this study and the observed values of $\bar{u}_{\text {max }}$ near the top of the canopy.

\begin{tabular}{|c|c|c|c|c|c|c|c|}
\hline \multirow[b]{2}{*}{ Run } & \multirow[b]{2}{*}{$\begin{array}{l}T \\
(\mathrm{~s})\end{array}$} & \multirow[b]{2}{*}{$\begin{array}{l}U_{\infty}^{r m s} \\
(\mathrm{~cm} / \mathrm{s})\end{array}$} & \multicolumn{5}{|c|}{$\bar{u}_{\max }(\mathrm{cm} / \mathrm{s})$} \\
\hline & & & RL & $\mathrm{RM}$ & $\mathrm{RH}$ & $\mathrm{FM}$ & $\mathrm{FH}$ \\
\hline 1 & 9 & 3.0 & 0.56 & 0.95 & 1.15 & - & - \\
\hline 2 & 9 & 4.4 & 1.14 & 1.59 & 2.18 & 0.64 & - \\
\hline 3 & 8 & 5.6 & 0.49 & 2.00 & 2.35 & 2.39 & 3.54 \\
\hline 4 & 9 & 5.9 & 1.65 & 2.69 & 3.66 & - & 3.19 \\
\hline 5 & 6 & 8.2 & 2.07 & 3.35 & 4.68 & - & 4.27 \\
\hline 6 & 8 & 7.7 & 1.71 & 3.15 & 3.81 & 2.79 & 5.43 \\
\hline 7 & 9 & 7.5 & 2.50 & 3.37 & 3.60 & - & 4.20 \\
\hline 8 & 8 & 9.8 & 2.63 & 3.19 & 3.51 & 4.36 & 7.22 \\
\hline 9 & 6 & 9.4 & 2.83 & 5.40 & 6.86 & 4.87 & 6.90 \\
\hline 10 & 9 & 11.4 & 2.35 & 3.98 & 5.52 & 5.21 & 6.25 \\
\hline 11 & 5 & 14.9 & 4.25 & 7.60 & 8.01 & 6.61 & 9.40 \\
\hline 12 & 9 & 11.3 & 3.65 & 5.00 & 6.16 & 5.40 & 8.51 \\
\hline 13 & 8 & 12.1 & 2.95 & 3.68 & 4.83 & 5.19 & - \\
\hline 14 & 6 & 15.6 & 4.36 & 7.49 & 5.66 & 6.76 & 10.17 \\
\hline 15 & 8 & 14.7 & 2.60 & 4.56 & - & 6.17 & 8.91 \\
\hline 16 & 5 & 19.0 & 4.45 & 9.41 & 10.30 & 7.25 & 13.40 \\
\hline 17 & 6 & 18.8 & 4.67 & 8.95 & 10.99 & 8.36 & 11.83 \\
\hline 18 & 8 & 17.0 & 3.29 & 7.10 & - & 7.51 & 9.17 \\
\hline 19 & 6 & 21.5 & 4.60 & 9.04 & 11.50 & - & - \\
\hline
\end{tabular}


Figure 1. 
(a)

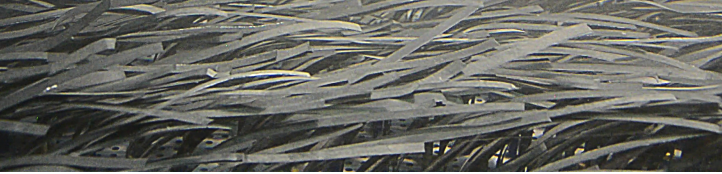

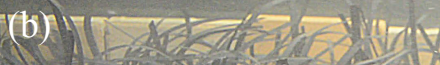

(2) 67 (1)

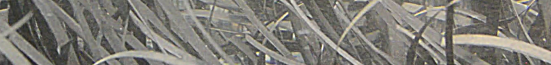

iis $>$ SRe

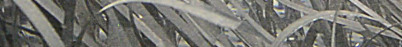

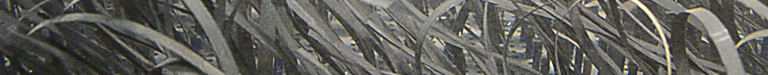

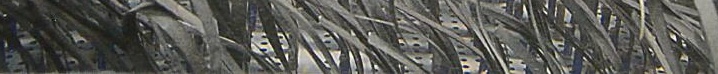


Figure 2. 


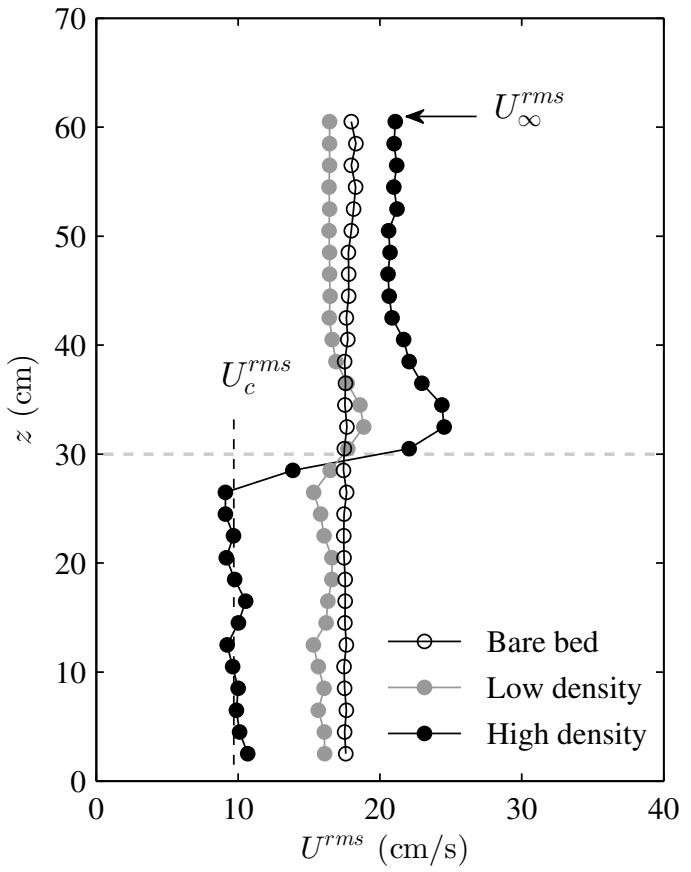


Figure 3. 
(a) Lagrangian frame

(b) Eulerian frame

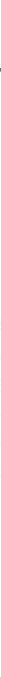


Figure 4. 


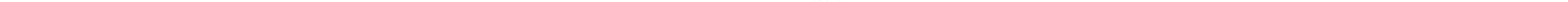


Figure 5. 
(a)

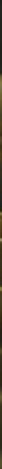

(b)

st

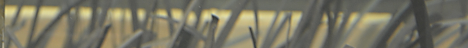
$1 \times 2 \times 3+2,2$

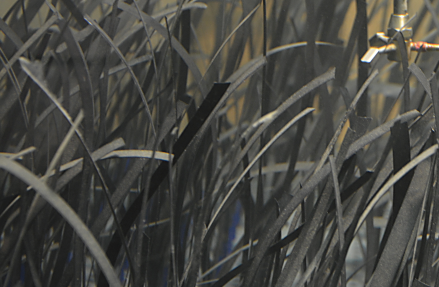
$=$

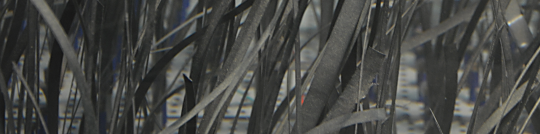
M H D

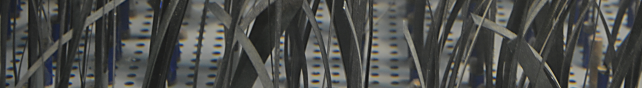
iff $-1, \backslash=4$ $M A=$ 14 
Figure 6. 


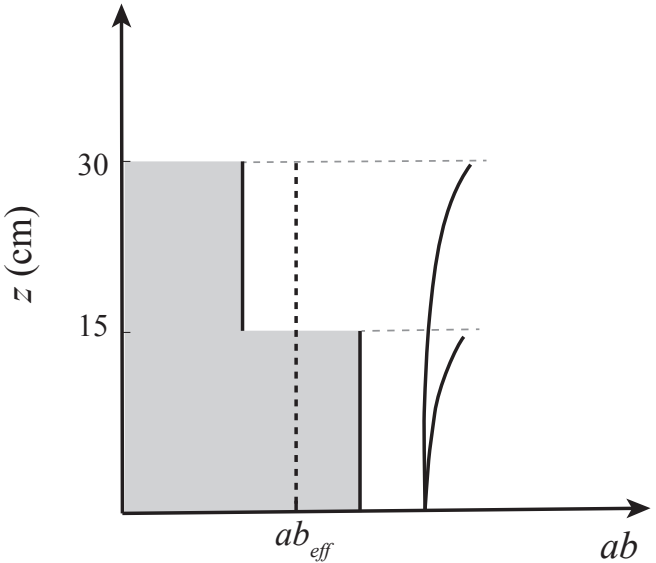


Figure 7. 

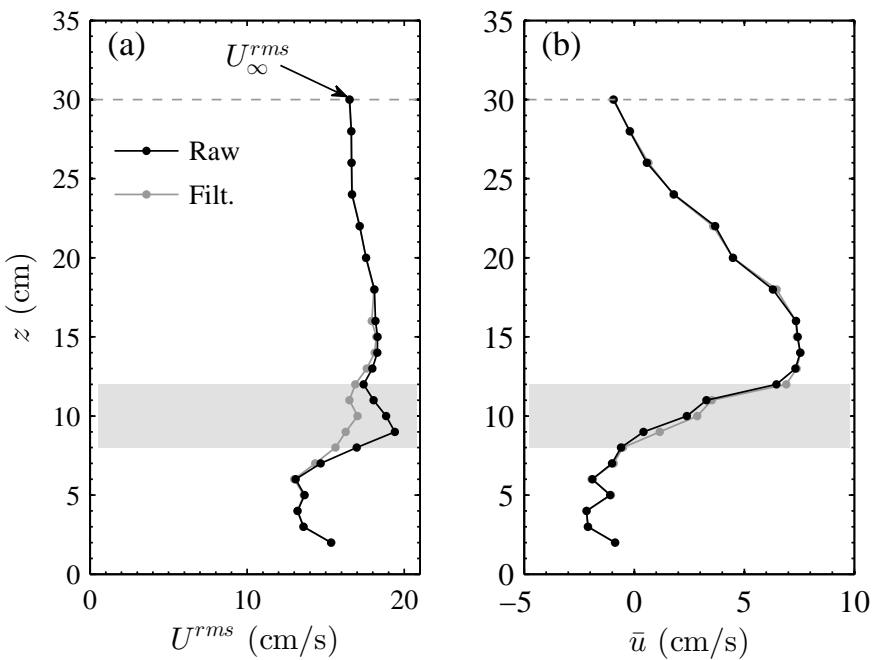
Figure 8. 


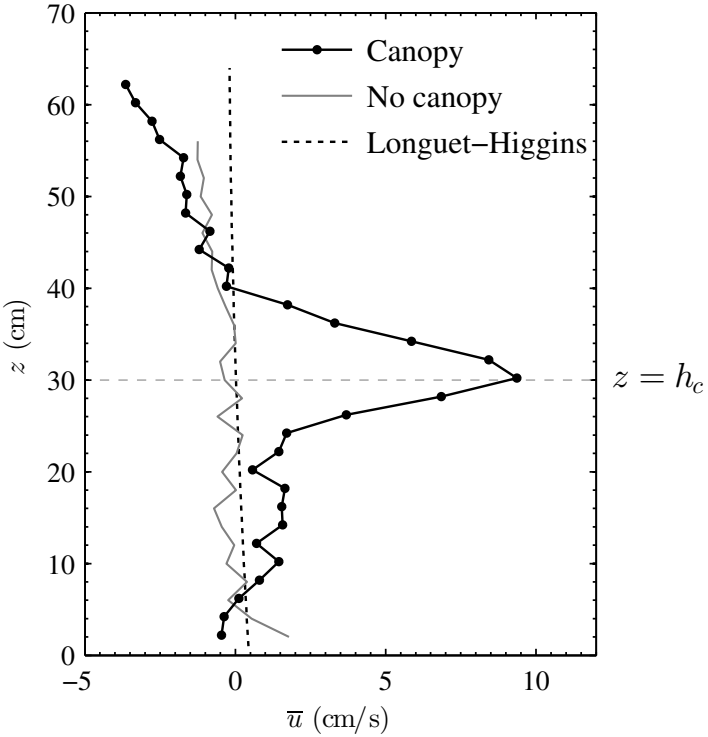


Figure 9. 

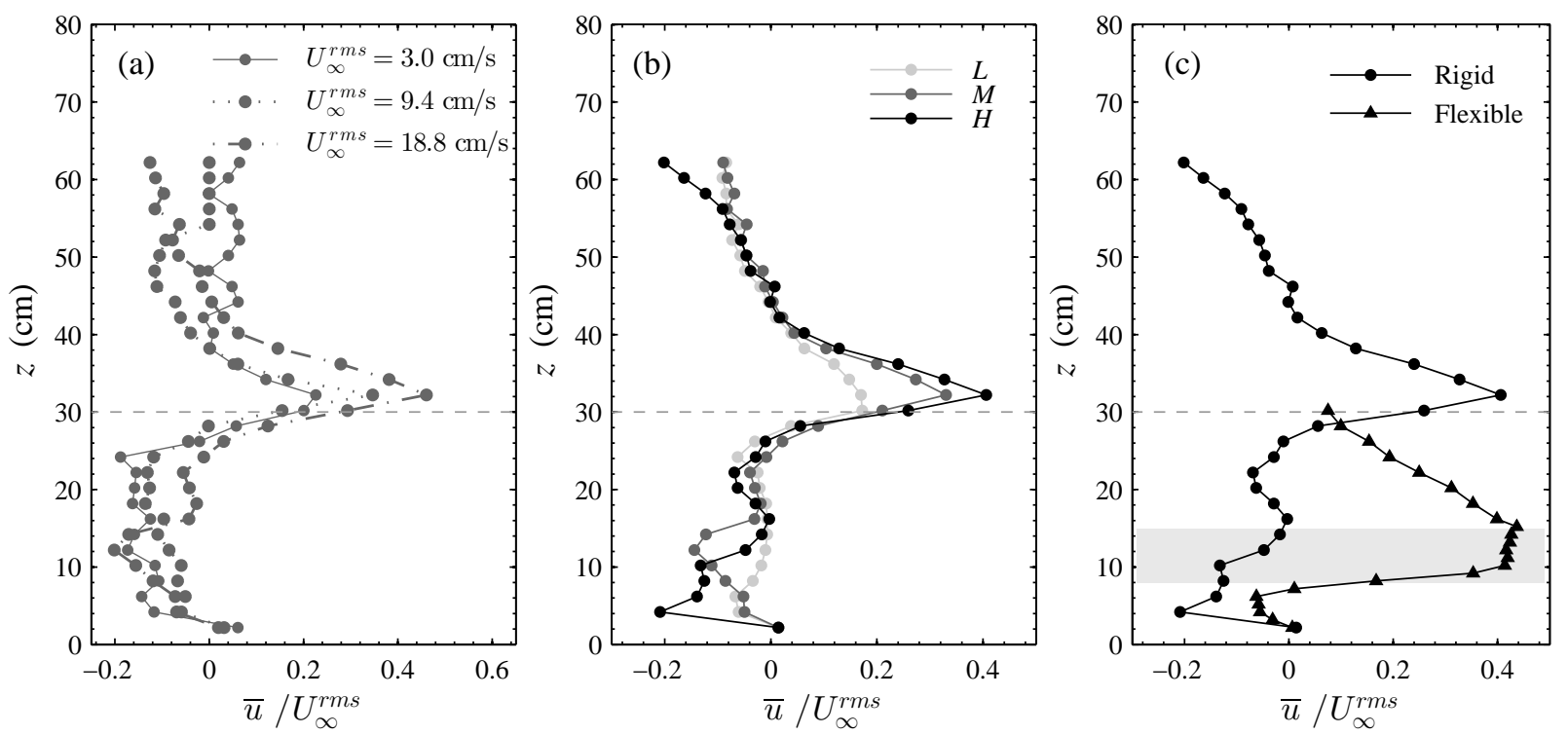
Figure 10. 

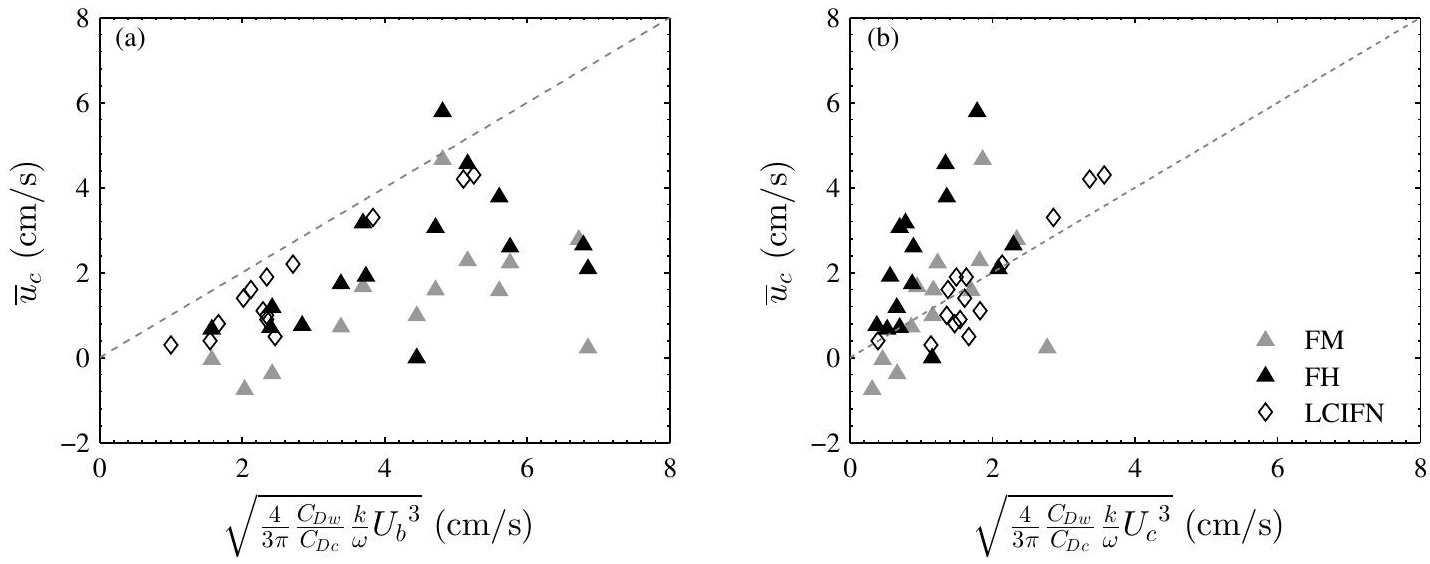
Figure 11. 


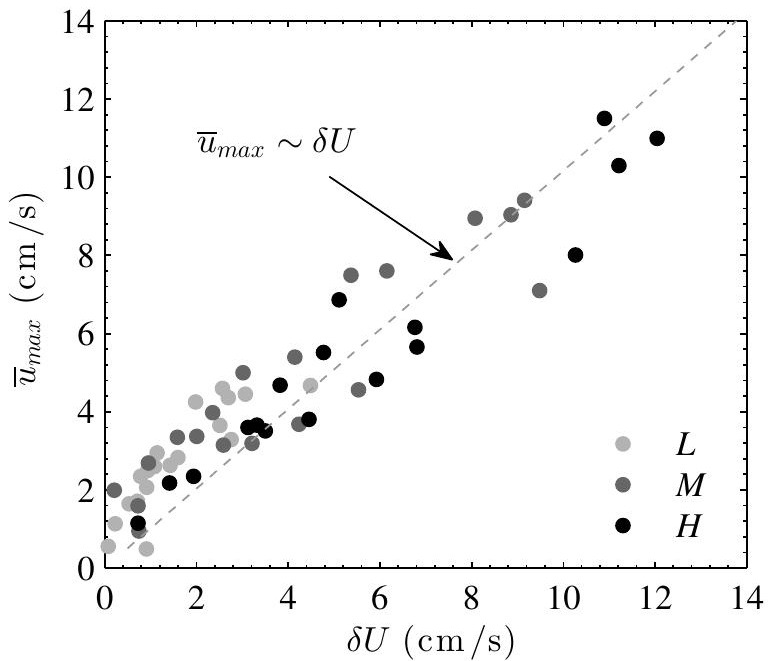


Figure 12. 


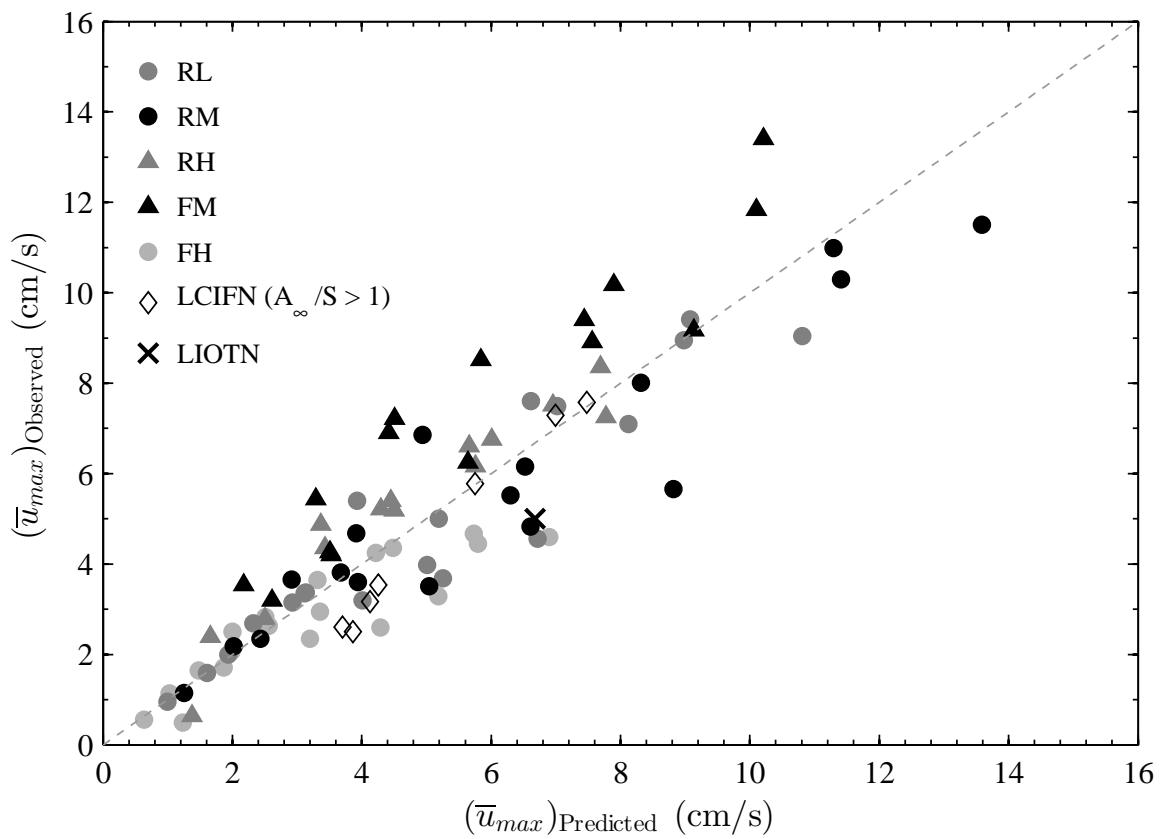


Figure 13. 


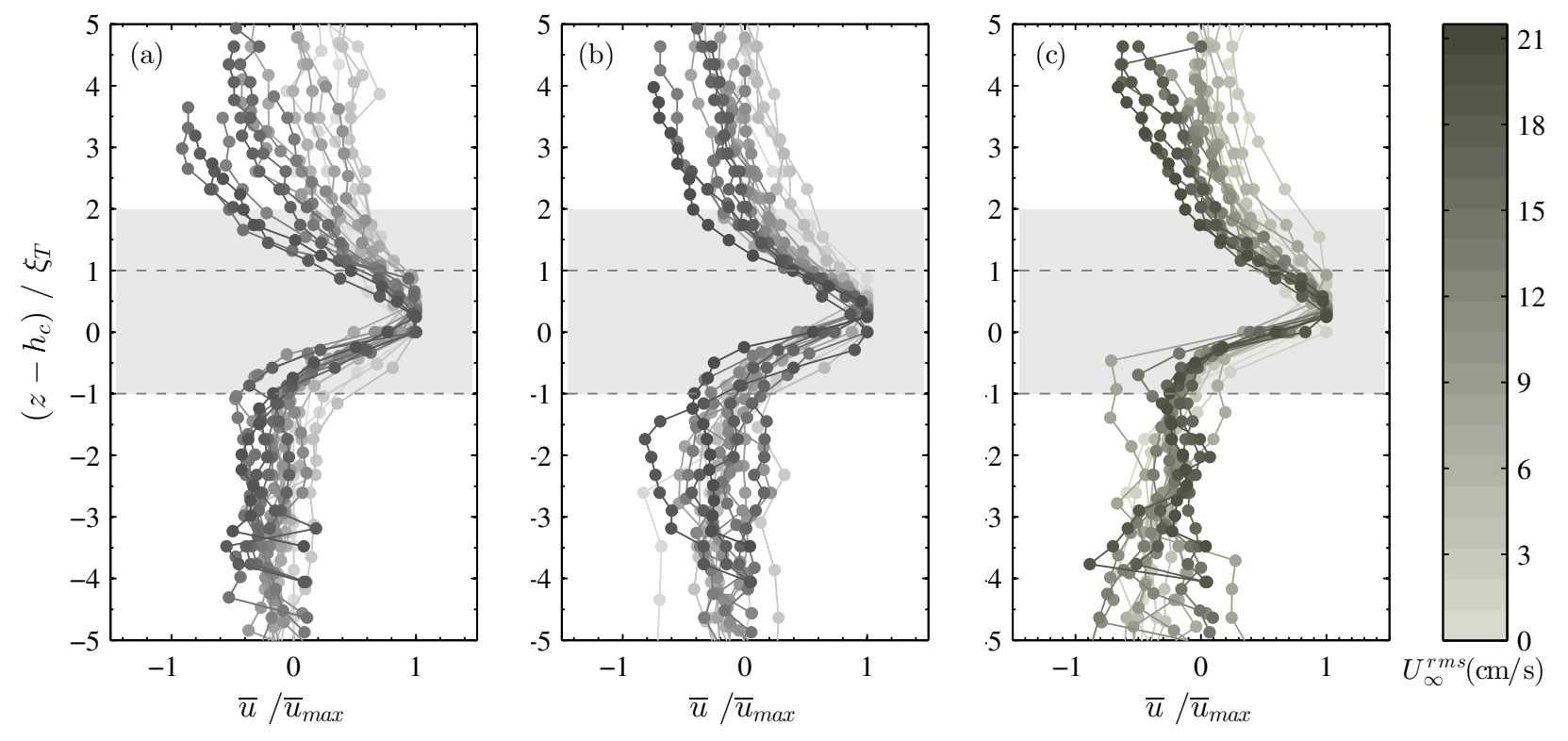


Figure 14. 


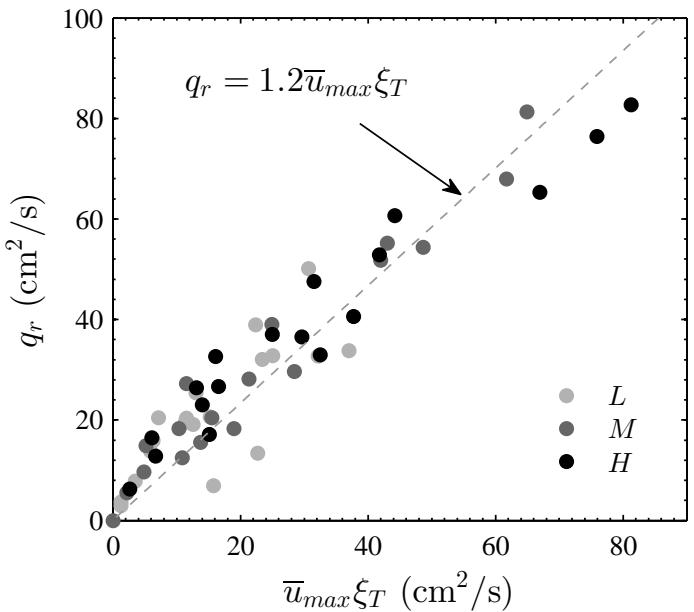


Figure 15. 


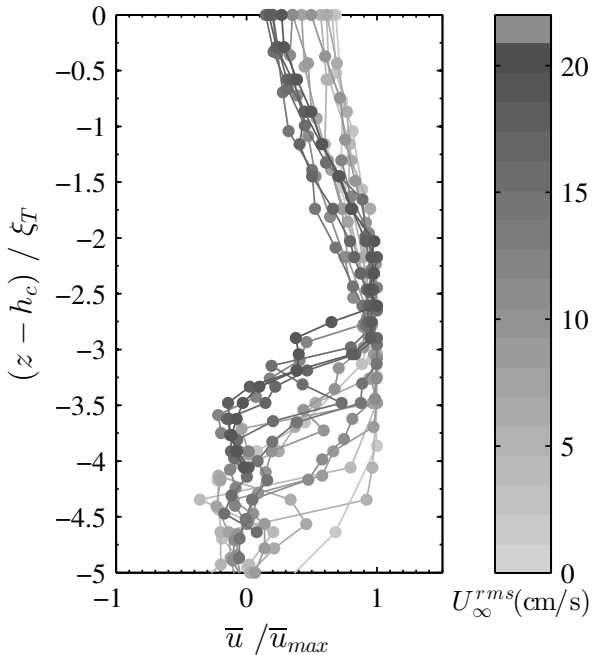


Figure 16. 


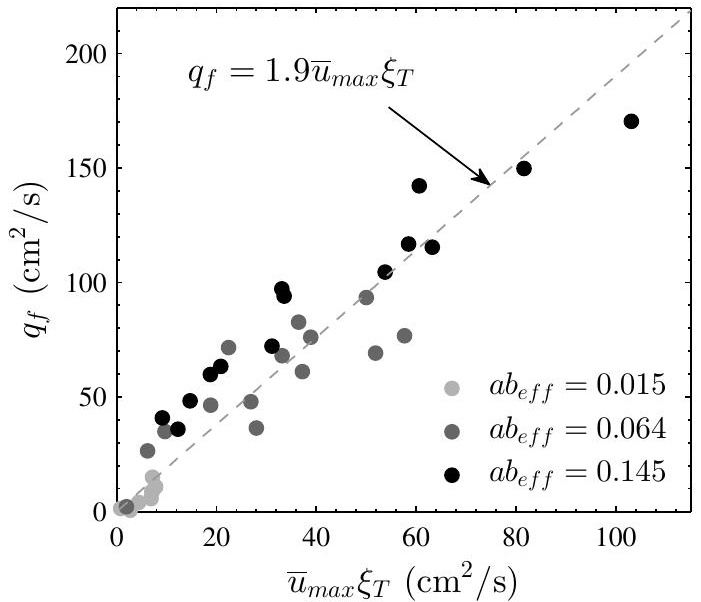

